\title{
Contabilidade das operações de leasing: análise de possíveis ocorrências de lobbying no processo de emissão da IFRS 16
}

\section{Resumo}

Objetivo: O estudo pretende analisar a potencial existência de lobbying no processo de substituição da International Accounting Standard (IAS) 17 pela International Financial Reporting Standard (IFRS) 16, emitidas pelo International Accounting Standards Board (IASB) e relativas às locações. Método: Foram recolhidas 641 comment letters submetidas à consulta pública no âmbito do Exposure Draft revisto (2013). O estudo adota a análise de conteúdo como método, sendo os dados posteriormente submetidos a técnicas de análise estatística univariada e bivariada.

Resultados: Os resultados sugerem a existência de lobbying a partir da constatação de divergências significativas entre entidades financeiras e não financeiras no que diz respeito às questões principais da norma, relacionadas com o reconhecimento e com o modelo único de contabilização das locações.

Contribuições: Aferir a existência de diferenças significativas de opinião indiciadoras de lobbying no âmbito de um projeto de substituição de norma promovido pelo Iasb e, em função dos distintos interesses envolvidos (lobbies), constitui, assim, o principal contributo da presente investigação.

Palavras-chave: Comment Letters, Leases, Lobbying, IASB, IFRS 16.

\begin{abstract}
Fábio Henrique Ferreira de Albuquerque Doutorado em Ciências Económicas e Empresariais pela Universidade de Extremadura e Professor no Instituto Superior de Contabilidade e Administração de Lisboa. Contato: Av. Miguel Bombarda, 20, Lisboa, Portugal, CEP: 1069-035. E-mail: fhalbuquerque@iscal.jpl.pt
\end{abstract}

Manuela Maria Marcelino Mestrado pelo Instituto Superior de Contabilidade e Administração de Lisboa e Técnica Superior na Universidade de Lisboa. Contato: Av. Professor Gama Pinto, Lisboa, Portugal, CEP: 1649-003. E-mail: mmarcelino@ff.ulisboa.pt

Nuno Miguel Barroso Rodrigues Mestrado pelo Instituto Superior de Contabilidade e Administração de Lisboa e Professor na Universidade dos Açores. Contato: Rua Mãe de Deus, Ponta Delgada, Portugal, CEP: 9500-321. E-mail: nuno.mb.rodrigues@uac.pt

António José Rodrigues de Almeida Cariano Mestrado pelo Instituto Superior de Contabilidade e Administração de Lisboa e Professor no Instituto Superior de Contabilidade e Administração de Lisboa. Contato: Av. Miguel Bombarda, 20, Lisboa, Portugal, CEP: 1069-035.

E-mail: ajcariano@iscal.jpl.pt 


\section{Introdução}

As locações representam uma atividade importante para distintas entidades, sendo um meio de obter financiamento, acesso a ativos e reduzir a exposição de uma entidade aos riscos de propriedade de ativos. Nesse sentido, é importante que os utilizadores das demonstrações financeiras tenham um quadro completo e compreensível das atividades das locações de uma entidade (International Financial Reporting Standards (IFRS) Foundation, 2013).

Os modelos contabilísticos existentes na International Accounting Standards (IAS) 17 Locações exigiam que os locatários e os locadores classificassem as suas locações como locações financeiras ou locações operacionais, com distintos modelos de contabilização. Tal distinção não satisfazia às necessidades dos investidores, na medida em que a dependência da qualificação das locações resultaria em distintos tratamentos nas demonstrações financeiras, sendo, nalguns casos, apresentados no balanço e, noutros, apenas refletidos na demonstração dos resultados do período em que as rendas são contabilizadas como gastos (Lloyd, 2016). Como resultado dessa divergência, os investidores frequentemente ajustavam as demonstrações financeiras dos locatários para reconhecer ativos e passivos que se encontravam "fora do balanço", procedendo ao ajustamento de indicadores relevantes na análise económico-financeira das entidades (IFRS Foundation, 2016a).

Donkersley, Ravelli e Buchanan (2016) fazem notar a dificuldade, por vezes existente, de proceder-se a tal ajustamento relativamente às informações que se encontram fora do balanço, devido à ausência dessa informação, impossibilitando aos investidores uma imagem plena da posição financeira de uma entidade e uma apropriada comparação entre as distintas entidades (Donkersley et al., 2016; IFRS Foundation, 2016; Lloyd, 2016). No entanto, com a introdução da IFRS 16, norma que substituirá a atual IAS 17 de mesma designação (Leases) e interpretações relacionadas, tal recurso deixa de ser necessário, na medida em que, quer o balanço, quer o anexo passarão a apresentar informação sobre tais operações, isto é, sobre os contratos de locação realizados pelos locatários.

Nesse sentido, a IFRS 16 então aprovada elimina a tradicional classificação das locações como operacionais ou financeiras sob o ponto de vista dos locatários, introduzindo um modelo único de contabilização. Tal modelo reflete que as locações resultam na obtenção de um direito de usar o ativo por uma entidade no princípio da locação por contrapartida de um passivo resultante da obrigação (financiamento obtido) de pagar um conjunto de rendas ao longo do tempo. Nesse sentido, significa em termos práticos a adoção, por parte dos locatários, de um tratamento único e similar ao já previsto na atual IAS 17 para as locações financeiras, com algumas exceções. Para os locadores, no entanto, mantém-se genericamente a necessidade de proceder-se à já atual classificação das locações previstas naquela mesma norma: operacionais ou financeiras.

A IFRS 16 é aplicável aos períodos que se iniciem em ou após $1^{\circ}$ de janeiro de 2019 , não tendo sido endossada, até a data, pela União Europeia. Pretende-se que tais alterações aumentem a transparência do relato financeiro, indo ao encontro dos interesses dos investidores e outros stakeholders, melhorando, consequentemente, o processo de tomada de decisão baseada nessa informação (IFRS Foundation, 2016; Lloyd, 2016). Nas palavras do IFRS Foundation (2016), na base do desenvolvimento conjunto da nova norma entre o International Accounting Standards Board (Iasb) e o Financial Accounting Standards Board (Fasb) encontrava-se, de facto, uma preocupação única no que concerne à falta de transparência para as distintas partes interessadas no relato financeiro, incluindo os investidores, no que diz respeito às operações de locação. Esta mesma preocupação fora expressa em 2005 pelo Securities Exchange Comission (SEC), organismo regulador da bolsa dos Estados Unidos da América (EUA) e homólogo da Comissão do Mercado de Valores Mobiliários (CMVM) em Portugal. 
O processo que resultou na emissão da IFRS 16 passou por diversas etapas, que incluiram três consultas públicas sobre as propostas apresentadas pelo Iasb, nomeadamente: a emissão de um Discussion Paper (DP) em 2009; a emissão do primeiro Exposure Draft (ED) em 2010; e, por fim, um ED revisto, em 2013. O processo passou, ainda, por centenas de reuniões e workshops - nos quais, entre outras matérias, foram detalhadamente discutidos os custos de implementação - round tables (15 das quais públicas e com a presença de stakeholders entre os membros do Iasb e do Fasb) e outras atividades de divulgação (IFRS Foundation, 2016). Nesse mesmo processo, foram ouvidas as diferentes partes mais diretamente relacionadas com os impactos da norma (locadores e locatários), assim como utilizadores e preparadores das demonstrações financeiras, organismos reguladores e emissores de normas de contabilidade, relato financeiro, e empresas ligadas à Contabilidade e Auditoria espalhadas em vários países. Um grupo de trabalho (working group) foi ainda criado pelo Iasb e pelo Fasb no sentido de, adicionalmente, obter-se acesso à experiência prática e expertise nessa matéria (IFRS Foundation, 2016).

No processo de discussão pública, a questão fulcral consistia na aceitação do reconhecimento de todas as locações no balanço das entidades locatárias, o que seria feito através de um único modelo de contabilização, como se veio, de facto, a materializar na IFRS 16. De acordo com o IFRS Foundation (2016), foi obtido na generalidade suporte para a alteração proposta. Apesar disso, não deixou de ser recebida a proposta de manutenção da forma atualmente prevista na IAS 17 (por outras palavras, o não reconhecimento ou o off balance sheet de algumas locações, as operacionais), incrementando ou melhorando, apenas, os requisitos de divulgação. Tal proposta foi, no entanto, recusada considerando os argumentos anteriormente apresentados relativos à nova abordagem: aumento da transparência, comparabilidade e redução da necessidade de ajustamentos à informação reportada pelas entidades. Sobre o modelo único de contabilização, então aprovado no final do processo, ou a aplicação de diferentes modelos propostos ao longo do desenvolvimento do projeto, as opiniões mostraram-se mais divergentes. Apesar disso, a maioria das opiniões destacou a grande complexidade relativamente à proposta de aplicação do modelo dual de contabilização que fora proposto pelo Iasb, que distinguia as locações de bens imóveis da locação de outros ativos.

O processo de normalização do Iasb (due process) permite a todos os interessados a possibilidade de participar nas discussões públicas e a emissão de opinião, nomeadamente por meio de comment letters (Carvalho, Albuquerque, Texeira Quirós \& Justino, 2015), onde o exercício do lobbying se pode materializar. O conceito de lobbying é um conceito muito abrangente, pelo que na prática, e devido a restrições metodológicas, a utilização de comment letters em resposta à consulta pública dos órgãos normalizadores é considerada uma estratégia de lobbying (Santos \& Santos, 2014). Na literatura, são já vários os estudos que têm como objetivo identificar as estratégias de lobbying utilizados pelos diversos grupos de interesse e/ou as diferenças de opinião no contexto da emissão ou revisão de uma nova norma, nomeadamente, Carvalho et al. (2015), Ginner e Arce (2012), Jorissen, Lybaert, Orens, e Van Der Tas (2012), entre outros.

O objetivo deste estudo passa por analisar se as opiniões contidas nas 641 comment letters submetidas à consulta pública no âmbito do ED revisto (2013), com período compreendido entre 16 de maio e 13 de setembro de 2013, para a contabilização dos contratos de locação apresentam diferenças significativas consoante a qualificação atribuída aos respondentes, indiciadoras da existência de lobbying. As respostas obtidas tiveram por base as doze (12) questões-chave relacionadas, entre outros, com o âmbito, reconhecimento, mensuração, divulgação e regras de transição dos contratos de locação, constantes no ED revisto (2013). Distintamente de outros estudos nessa linha de investigação, procurar-se-á analisar igualmente o aparente comportamento dos respondentes face às perguntas apresentadas, tendo em conta o potencial interesse que tais questões despertam à luz das distintas temáticas que lhes estão subjacentes.

O ponto seguinte deste artigo apresenta o enquadramento teórico que suporta o desenvolvimento do presente estudo. 


\section{Enquadramento teórico}

O Iasb é um organismo sem autoridade eleita ou outra autoridade governamental, pelo que um processo de elaboração de normas transparente com a participação dos constituintes é um elemento-chave da legitimidade do Iasb (Kenny \& Larson, 1993; Jorissen et al., 2012). Larson (2007) refere que a participação é um método para que uma organização obtenha maior legitimidade e sucesso; a falta de participação, por sua vez, sugere uma falha no processo (Giner \& Arce, 2012). Na mesma ótica, Kort (2011) refere que no cumprimento dos seus deveres normativos, os normalizadores tentam ser tão abertos e transparentes quanto possível, devido a não existir a presença de nenhuma autoridade eleita ou governamental para monitorar os membros, pelo que a participação do público neste processo é exigida.

O Iasb desenvolve as suas normas ao longo de um due process, no qual estão previstas várias oportunidades para as diferentes partes interessadas (por exemplo, preparadores, auditores, contabilistas ou analistas financeiros) expressarem a sua opinião e influenciarem as normas da agenda do Iasb (Orens, Jorissen, Lyabert \& Van Der Tas, 2011). De acordo com Larson (2008), embora tenha ocorrido grandes avanços em direção à convergência das normas contabilísticas, existe a preocupação de que as pressões políticas, se forem eficazes, possam criar normas internacionais de contabilidade que nem sempre atuam no sentido do melhor interesse dos investidores e de outros stakeholders.

$\mathrm{Na}$ ótica de Asekomeh, Russell e Tarbert (2006), os processos de elaboração das normas, além de estabelecerem um conjunto de regras contabilísticas, trazem mudanças (incluindo os custos e/ou benefícios) para as partes interessadas. Assim, em virtude de a contabilidade afetar a alocação de escassos recursos económicos, os stakeholders (por exemplo, administração, governo ou acionistas) têm interesse em modelar as novas normas contabilísticas (Hill, Shelton \& Stevens, 2002).

Todas as partes interessadas, tais como os preparadores, auditores e utilizadores têm interesses diferentes e muitas vezes contraditórios, pelo que se torna quase impossível desenvolver uma norma contabilística que seja satisfatória para todas as partes. Assim, todas as partes interessadas vão tentar convencer os normalizadores para tornar as regras que maximizam a sua utilidade (Kort, 2011). Uma maneira de influenciar o Iasb é argumentar a favor ou contra as alterações de normas de contabilidade propostas em comment letters que são submetidas ao Iasb, sendo esta a forma mais observável de feedback obtido pelo Iasb (Hartwig, 2012).

As atividades de lobbying são habitualmente realizadas sempre que as novas normas de contabilidade propostas ou alteradas afetem as informações contabilísticas contidas nos relatórios financeiros, o que por sua vez pode ter consequências económicas no âmbito da Contabilidade (Hartwig, 2012). O lobbying pode ser definido como qualquer tentativa de indivíduos ou grupos de interesses privados de influenciar as decisões de uma organização política (Chatham, Larson \& Vietze, 2010).

De acordo com o estudo efetuado por Procházka (2015), o Iasb tende a sucumbir à pressão se o lobby for expressivo (avaliado pelo número de comment letters enviadas) em relação a outros projetos e, de acordo com evidências adicionais sobre a capacidade geral de quem o exerce no sentido de influenciar a decisão dos normalizadores, empurrá-los para a revisão substancial de um projeto, ou mesmo parar completamente o projeto em questão.

Hansen (2010), por sua vez, refere que o sucesso do lobby está positivamente relacionado com a credibilidade de quem fornece informação e a sua capacidade de transmiti-la, tendo encontrado evidências de que o sucesso do lobby está associado ao seu impacto na viabilidade do Iasb, avaliado por suas contribuições financeiras e pela dimensão do mercado de capitais do país de origem.

Chatham et al. (2010), contrariamente, referem que apesar da participação das diferentes partes no processo de discussão pública, é improvável que as propostas apresentadas sejam diretamente afetadas pelas mudanças propostas. A falta de justiça (real ou percebida) poderia comprometer a perceção da legitimidade processual do processo e, em última instância, prejudicar a legitimidade cognitiva do Iasb (Bamber \& McMeeking, 2016). 
Kothari, Ramanna e Skinner (2010) referem que os reguladores têm ideologias próprias (por exemplo, eles acreditam fortemente na primazia do balanço ou no justo valor), estando, no entanto, abertos a lobbying de constituintes com conhecimentos específicos em determinada matéria. Nesse sentido, o lobby pode não ser visto como uma forma explícita de suborno, mas, sim, um mecanismo através do qual os reguladores são informados sobre a envolvente, incluindo política relacionada com a matéria. Por outras palavras, os grupos de interesse pressionam os reguladores no sentido de transmitir o seu conhecimento específico sobre as questões que estão sendo regulamentadas (Kothari et al. 2010). Assim, e na ótica de Santos e Santos (2014), o lobby não deve ser visto, necessariamente, como uma atitude ilegal ou imoral, mas sim um mecanismo através do qual o regulador obtém conhecimento das práticas e politicas adotadas pelas empresas.

\subsection{Teorias relacionadas com o lobbying no contexto do due process}

O recurso ao lobbying no contexto do due process encontra suporte na literatura contabilística a partir de distintas teorias.

Tendo por base a teoria positiva da Contabilidade desenvolvida por Watts e Zimmerman (1978), a existência de incentivos económicos por parte dos agentes leva a que os mesmos influenciem os organismos reguladores com vista à obtenção de normas que beneficiem os seus interesses, nomeadamente por meio do lobbying. Os autores referem que as partes interessadas tentam influenciar as normas regulatórias para maximizar a sua utilidade, e nessa assunção, o lobby praticado sobre as normas baseia-se nos interesses particulares de cada stakeholder. Nesse sentido, os ajustamentos derivados da alteração de uma norma contabilística só serão efetuados até ao ponto que o custo marginal do ajustamento é igual aos benefícios marginais (Watts \& Zimmerman, 1978).

De acordo com Asekomeh et al. (2006), esta abordagem é consistente com a teoria da Agência (Jensen \& Meckling, 1976 e Fama, 1980) e a teoria do Comportamento Racional (Klein, 1946), as quais sugerem que cada grupo de interessados irá tentar influenciar as decisões do normalizador de acordo com o seu melhor interesse, ou seja, de forma a maximizar os seus próprios interesses em relação aos de outras partes interessadas.

Similarmente, a teoria económica da regulação proposta por Stigler (1971) está comprometida com os fortes pressupostos da teoria económica em geral, a partir dos quais as pessoas procuram atingir os seus próprios interesses de forma racional, utilizando para o efeito dos grupos politicamente eficazes (Posner, 1974). Em função deste pressuposto, a teoria também é conhecida como teoria dos grupos de interesse, visto que a regulação procura atender os interesses dos grupos que forem politicamente mais eficazes em convencer o regulador a agir em benefícios deles (Santos \& Santos, 2014). Os autores referem ainda que as escolhas contabilísticas se relacionam com a teoria dos grupos de interesse devido ao facto de as políticas contabilísticas serem estabelecidas tendo por base os diversos incentivos económicos existentes e que os mesmos se fazem presentes no processo de regulação. Alinhando as escolhas contabilísticas com o processo de regulação contabilística, os gestores teriam incentivos económicos para realizar lobbying contra ou a favor de uma regulação contabilística, de modo a influenciar o órgão emissor a optar por modelos contabilísticos que lhes permitam, por exemplo, reduzir ou diferir o pagamento de empréstimos; diminuir os custos políticos e a produção de informações (divulgação); ou, ainda, aumentar o recebimento de bónus (Santos \& Santos, 2014). 
O processo de lobbying tem sido igualmente estudado sob a perspetiva da teoria institucional. De acordo com Larson (2002), a referida teoria investiga as relações das organizações com os indivíduos e outras organizações, sugerindo que a ação organizacional deve ser entendida como uma tentativa de alcançar a legitimação social e manter a credibilidade com os constituintes externos (Fogarty, 1992). Kenny e Larson (1993), de acordo com Scott (1987), referem que a teoria Institucional coloca as organizações dentro de um ambiente social e reconhece explicitamente as influências e interações do ambiente social externo sobre as atividades internas da organização. Bengtsson (2011) refere que a teoria Institucional tem sido utilizada em pesquisas sobre a definição de normas contabilísticas para complementar as estruturas explicativas da teoria Racional e da Economia Política, com foco na forma como as pressões exercidas influenciam a adoção das normas contabilísticas.

A teoria da legitimidade, por sua vez, foi utilizada por Bamber e McMeeking (2016) para explicar os resultados e questionar as implicações de eventuais enviesamentos sob o ponto de vista do Iasb, em estudo no qual exploram o due process relativamente ao processo de definição de normas contabilísticas com foco nos níveis relativos de influência das partes interessadas e jurisdicionais. Os autores criaram um sistema de codificação ponderado para analisar o conteúdo das comment letters, avaliando as diferenças na taxa de aceitação dos comentários feitos pelas partes interessadas e por jurisdições. Por fim, analisaram a documentação posta à discussão pública pelo Iasb que lança luz sobre o processo de tomada de decisão. Com base nos resultados obtidos, Bamber e McMeeking (2016) verificaram que as empresas de contabilidade parecem ter significativamente menos influência do que outras partes interessadas, que o Iasb reage menos favoravelmente às propostas do Reino Unido, mas que os comentários dos EUA são provavelmente mais discutidos.

\subsection{Estudos que analisam o lobbying no contexto do due process}

Tendo como objeto de análise as comment letters submetidas no âmbito de processos de discussão pública de alteração ou revisão normativa propostos por organismos normalizadores, identificam-se estudos que analisaram as respostas obtidas por parte de diversos stakeholders em distintas áreas e objetivos. Tais estudos não se encontram, no entanto, necessariamente associados às teorias anteriormente mencionadas.

Giner e Arce (2012) analisaram o comportamento de lobby e a sua influência na tomada de decisões por parte do Iasb, tendo por base uma análise de conteúdo de 539 comment letters em resposta aos três períodos de consulta pública anteriores à emissão da IFRS 2 Share Based Payments. As comment letters foram classificadas em seis grupos de respondentes, nomeadamente, reguladores, associações profissionais, utilizadores, preparadores, consultores e académicos, tendo-se focado sobre três opiniões chave (reconhecimento, critério de mensuração, e data de referência) e o tipo de argumento dado para justificação (concetual ou baseado em consequências económicas). Os preparadores e consultores constituíram os únicos grupos que usaram argumentos de consequências económicas para discordar, mas também adotaram argumentos conceituais. O Iasb, no entanto, considerou apenas argumentos conceituais, não tendo sido identificadas partes interessadas com influência dominante sobre as decisões adotadas.

Allen, Ramanna e Roychowdhury (2014) analisaram o lobby praticado pelos auditores através das comment letters durante o período de 1973 a 2006 pelo Fasb. Os incentivos dos auditores das Big N (Ernst \& Young, Deloitte Touche, KPMG e PwC) foram caracterizados a partir de três fontes distintas, nomeadamente: o desejo de gerir os custos esperados de litígio e regulatórios, o desejo de atender à preferência de flexibilidade por parte dos seus clientes de auditoria e o desejo de apoiar o FASB na sua agenda conceptual sobre a contabilização do justo valor. Os resultados indicaram um suporte para os custos de litígio esperados e a ameaça de escrutínio regulamentar como sendo importantes orientadores do lobby praticado pelos auditores. Na presença dessas forças, as Big N são mais propensas a enfatizar a sua preocupação em relação à diminuição da fiabilidade das normas propostas. Os resultados confirmam que o lobbying praticado pelas Big $\mathrm{N}$ incide mais sobre as preocupações relativas à fiabilidade das normas propostas durante regimes de litígio que reduzem a eventual imputação de responsabilidade ao auditor. 
Orens et al. (2011) exploram se a atitude dos preparadores com vista ao lobbying é diferente consoante o contexto regulatório do país de origem dos preparadores. Ao comparar os padrões de participação de preparadores belgas (originários de um ambiente regulatório caracterizado por um padrão de contabilidade interna iniciado pelo governo) com preparadores do Reino Unido (onde os preparadores são convidados a participar do processo de definição de normas contabilísticas), verificaram que os métodos utilizados, a perceção sobre a eficácia dos métodos e as razões da não participação diferem entre os dois grupos de preparadores. Esta constatação sugere que o contexto regulamentar nacional dos preparadores pode afetar o comportamento dos preparadores na sua decisão de participar na definição de normas contabilísticas (Orens et al., 2011).

Carvalho et al. (2015) analisaram as diferenças em termos dos interesses profissionais a partir da participação de diferentes grupos de stakeholders no contexto da primeira fase do projeto de substituição da IAS 39, intitulada "Financial Instruments - Recognition and Measurement" pela IFRS 9, por sua vez intitulada "Financial Instruments". Os respondentes foram identificados consoante o grupo de stakeholders, tendo-se verificado a existência de diferenças significativas entre as respostas obtidas por parte dos distintos grupos envolvidos no processo, sobretudo entre o grupo dos preparadores financeiros e dos organismos reguladores e/ou normalizadores e as associações profissionais ligadas à contabilidade.

Larson e Brown (2001) investigaram a relação entre a posição dos grupos de interesse, por um lado, e as normas de contabilidade e as regras fiscais dos respetivos países de origem, por outro. A norma dos contratos de construção foi utilizada como objeto de estudo. O estudo encontrou uma associação entre as posições de lobbying dos inquiridos e as normas de Contabilidade e legislação fiscal do país de origem dos respondentes, fornecendo, assim, evidências que suportam a ideia de que os respondentes se opõem a mudanças no status quo (do relato financeiro ou em matéria fiscal), particularmente as mudanças que podem provocar consequências económicas no futuro.

Santos e Santos (2014) analisaram os fatores determinantes relativamente à submissão de comment letters no âmbito da audiência pública do DP Extractive Activities do Iasb, no sentido de identificar estratégia de lobbying na regulação contabilística do setor petrolífero. Os autores identificaram a dimensão da empresa como um fator determinante, indicando que existe uma maior probabilidade de o lobbying ser praticado por grandes empresas petrolíferas, que apresentaram uma propensão para a manutenção do status quo.

Hartwig (2012) analisou as posições dos preparadores e não preparadores em relação à contabilização da amortização do goodwill, por meio do estudo de 128 comment letters enviadas sobre o ED3 Business Combinations. Devido a consequências económicas, os preparadores demonstraram incentivos para perpetuar o lobby para a abordagem de não amortização e os não preparadores para a abordagem de amortização, existindo, assim, um maior apoio à amortização do goodwill por parte dos não preparadores. Os resultados demostraram, em linha com estudos anteriores, que os dois grupos usam argumentos baseados em frameworks, em vez de argumentos de consequências económicas, indicando que tanto os preparadores como os não preparadores apontam os pontos fortes e fracos sob esta abordagem, em detrimento das razões relacionadas com as atividades de lobbying, isto é, consequências que afetassem a versão final da norma.

Anantharaman (2015) analisou as comment letters submetidas ao Fasb no âmbito do ED $201 \mathrm{Bu}$ siness Combinations e posterior revisão, tendo por base a evolução da Statement of Financial Accounting Standards (SFAS) 141, de mesma designação, e da SFAS 142 Goodwill and Other Intangible Assets. Contrariamente às abordagens propostas pelo Fasb, a maioria dos respondentes se apresentou contrária à abolição do método da comunhão de interesses não em termos teóricos, mas em termos práticos, por resultar em consequências económicas negativas para as empresas de vários setores. No que concerne ao tratamento do goodwill, houve um maior apoio à abordagem de "amortização com imparidade" versus a abordagem de imparidade em exclusivo, sendo a visão dominante entre a maioria dos respondentes, particularmente das empresas de auditoria, a de que a última abordagem não seria fiável o suficiente para ser aplicável na prática. 
Do Carmo, Mussoi e Carvalho (2011) analisaram a influência dos grupos de interesse no âmbito do DP das locações, tendo por base as 302 comment letters recebidas no período de março a julho de 2009 , que resultou no ED emitido em agosto de 2010. Os respondentes foram classificados em preparadores (empresas e associações de empresas não ligadas à Contabilidade), profissionais da contabilidade (empresas e associações de empresas ligadas à Contabilidade), normalizadores e académicos. Algumas informações foram adicionadas a tais grupos, nomeadamente: o país de origem do respondente, o número de representantes nativos no board do Iasb, o montante total de financiamento do board efetuado pelas entidades do país do respondente e o índice de capitalização do mercado local. Com base em técnicas de regressão logística, os autores verificaram se as características dos respondentes influenciaram a posição manifestada pelo Iasb no ED sobre locações após a emissão do DP. Os resultados obtidos sugerem que apenas as opiniões de profissionais da contabilidade, normalizadores nacionais e académicos exerceram influência nas decisões tomadas pelo Iasb.

Também no âmbito das locações, Mellado-Bermejo e Esteban (2014) examinaram as comment letters submetidas no contexto do DP de 2009 e dos ED de 2010 e 2013, de modo a analisar a influência dos países na proposta de contabilidade de locações emitida pelo IASB e Fasb. Com base nas 1.746 comment letters recolhidas, os resultados obtidos identificaram diferenças significativas na intensidade de participação por país, sendo influenciada pelo rendimento, linguagem e proteção dos credores do país de origem.

Kort (2011), por sua vez, analisou a influência dos interesses próprios sobre as posições tomadas pelas empresas no processo de elaboração da mesma norma (locações). O estudo focou-se apenas nas comment letters enviadas pelos arrendatários, tendo por objetivo identificar se as características das empresas influenciam as respostas enviadas. A investigação examina as comment letters relativas ao DP de 2009 (105 respostas) e o ED de 2010 (149 respostas). Os resultados indicam que as obrigações em matéria de locações e o rácio de solvabilidade das empresas têm uma grande influência sobre os comentários enviados, indicando que eles se encontram distorcidos pelos interesses próprios das empresas, em detrimento do interesse público.

O ponto seguinte deste artigo divulga as hipóteses e linhas metodológicas definidas para a concretização do objetivo inicialmente definido, tendo em conta o enquadramento teórico apresentado nesse ponto.

\section{Hipótese e metodologia}

O presente estudo propõe-se a investigar as diferenças entre os grupos de stakeholders participantes nos processos de emissão/alteração de normas do Iasb por via das comment letters. Tais documentos são uma parte integrante do processo de normalização e contêm informações valiosas sobre as opiniões das partes, nomeadamente, emissores, profissionais da contabilidade e auditores, analistas de valores mobiliários, e outros (Anantharaman, 2015). Mellado-Bermejo e Esteban (2014) referem que as comment letters permitem aos investigadores compreenderem melhor as questões críticas acerca de uma nova norma, as suas características e o comportamento das partes que integram o processo. Além disso, permitem analisar a ligação entre as comment letters e a norma final. Esta é uma informação valiosa para o mercado, preparadores e utilizadores em geral, pois permite aferir a importância de fatores económicos e políticos no processo de normalização contabilística derivados de interesses particulares de determinado(s) grupo(s) de stakeholders (Mellado-Bermejo \& Esteban, 2014). Asekomeh et al. (2006) referem, no mesmo sentido, que as comment letters e as transcrições de audiências públicas proporcionam uma das formas mais fiáveis de evidência para estudos relacionados com o lobbying, por comparação às respostas obtidas a partir de estudos que utilizam o questionário. 
A recolha dos dados para este estudo foi efetuada por meio das comment letters de resposta ao ED revisto (2013) relativo ao projeto de substituição da IAS 17 pela IFRS 16. Georgiou (2004) sugere a existência de mais empresas a praticar lobby durante as etapas de consulta pública mais eficazes (por exemplo, período de exposição de um DP), comparativamente com os estágios iniciais do processo (por exemplo, a formação da agenda). Kort (2011) também identificou no seu estudo que as comment letters enviadas em uma fase inicial do processo de elaboração da norma são menos tendenciosas do que as enviadas posteriormente. Tendo em conta o anteriormente exposto, para atingir os objetivos inicialmente propostos, este estudo recorre às opiniões contidas nas comment letters submetidas à consulta pública no âmbito do ED revisto (2013), com período compreendido entre 16 de maio e 13 de setembro de 2013.

O estudo utiliza, assim, a análise de conteúdo como metodologia de pesquisa. Esta análise é definida por Krippendorff (1980) como um método de investigação que permite realizar inferências replicáveis e válidas a partir de dados, de acordo com o seu contexto. Weber (1990), por sua vez, define-a como um método de investigação que utiliza um conjunto de procedimentos com o objetivo de elaborar inferências a partir de determinado texto. Para o autor, a análise de conteúdo é particularmente útil, uma vez que permite transformar e codificar o texto no sentido da pesquisa a ser conduzida.

As respostas recolhidas foram então classificadas em função dos grupos de stakeholders respondentes. A referida classificação procura captar a existência de potenciais interesses particulares no tema em análise (locações), característicos da existência de lobbies, tal como se encontra subjacente à hipótese definida. Designadamente, Kort (2011) refere que, enquanto os organismos de normalização esperam que as empresas participem no processo de elaboração da norma tendo em conta o interesse público, a maioria das empresas critica as propostas de elaboração de novas normas contabilísticas com base no seu próprio interesse.

A amostra foi constituída inicialmente por 641 comment letters, tendo-se excluído um número correspondente a 39 respostas por não ter sido possível identificar qualquer posicionamento específico a pelo menos uma das questões levantadas. A Tabela 1 identifica a classificação proposta para os distintos grupos de stakeholders e o número de respostas (comment letters) recebidas de cada grupo.

Tabela 1

Classificação dos stakeholders respondentes e distribuição das respostas

\begin{tabular}{cccc}
\hline Código & Classificação das entidades & $\begin{array}{c}\text { Distribuição } \\
\text { absoluta }\end{array}$ & $\begin{array}{c}\text { Distribuição } \\
\text { relativa (em \%) }\end{array}$ \\
\hline NFI & Entidades não financeiras & 301 & 50,0 \\
\hline FIN & Entidades financeiras & 137 & 22,8 \\
\hline REG & Reguladores e associações profissionais & 132 & 21,9 \\
\hline OUT & Outros (académicos e preparadores particulares) & 32 & 5,3 \\
\hline & Total & 602 & 100 \\
\hline
\end{tabular}

A definição dos grupos baseou-se na identificação de interesses potencialmente comuns (característico dos lobbies) e na maior homogeneidade possível entre os elementos da população, sem prejuízo da identificação de uma participação minimamente representativa nesta. No grupo FIN (entidades financeiras) foram incluídas as entidades ligadas às instituições de crédito e sociedades financeiras, ao passo que o grupo NFI (entidades não financeiras) é composto por empresas cuja atividade ou negócio principal insere-se no âmbito das sociedades não financeiras. Assim, e na composição final, o grupo outros é o menos representativo, com cerca de 5\%, incluindo, fundamentalmente, preparadores em nome individual e académicos. Merece particular menção, nesse contexto, a tentativa de segregação dos seguintes elementos da população, que, no entanto, se demonstrou inviável face aos objetivos anteriormente descritos: 
- Auditores, particularmente os oriundos das empresas multinacionais de auditoria (incluídos no grupo das "entidades não financeiras"): tentativa inviabilizada pela reduzida participação de tais elementos na amostra;

- Associações profissionais (incluídos no grupo dos "reguladores e associações profissionais"): além da reduzida participação, nem sempre a distinção entre este grupo e o grupo dos reguladores é evidente, ao que se acresce o facto de que algumas associações apresentam em certas jurisdições competências de regulação contabilística; e

- Reguladores financeiros versus não financeiros (incluídos, conjuntamente, no grupo dos "reguladores e associações profissionais"): apesar do potencial interesse dessa classificação (tendo em conta o objetivo deste estudo), em diversos casos a classificação não se apresentava clara ou homogénea. A título de exemplo, reguladores de mercados de valores mobiliários poderão defender interesses, quer de entidades do setor financeiro, quer de entidades do setor não financeiro. Nesse sentido, como garantia de uma maior harmonização como grupo, e porque outras distinções se apresentaram inviáveis (baixas representatividades dos distintos grupos), optou-se pela agregação dessas observações num único grupo.

Doze questões foram propostas pelo Iasb na fase final do projeto, e que correspondem, de forma isolada ou agrupada, às variáveis deste estudo. A partir do conteúdo das referidas questões, propôs-se para efeitos de análise a agregação das mesmas em torno do seu conteúdo principal em matéria contabilística. Tal informação encontra-se descrita na Tabela 2.

Tabela 2

Variáveis: questões em discussão no ED revisto (2013)

\begin{tabular}{|c|c|c|}
\hline Código & Conteúdo da Questão (Q) & Temática \\
\hline Q1 & $\begin{array}{l}\text { Concorda com a definição de locação e requisitos propostos sobre como uma } \\
\text { entidade determinaria quando um contrato contém uma locação? }\end{array}$ & \multirow{8}{*}{$\begin{array}{l}\text { Questões principais } \\
\text { Critérios de } \\
\text { reconhecimento, } \\
\text { mensuração e } \\
\text { divulgação (incluindo } \\
\text { regras de transição) } \\
\text { no âmbito da } \\
\text { IFRS } 16\end{array}$} \\
\hline Q2 & $\begin{array}{l}\text { Concorda que o locatário deva aplicar um modelo contabilístico distinto, de } \\
\text { acordo com o consumo expetável de benefícios económicos incorporados no } \\
\text { ativo subjacente realizado pelo locatário? }\end{array}$ & \\
\hline Q3 & $\begin{array}{l}\text { Concorda que o locador deva aplicar um modelo contabilístico distinto, de acordo } \\
\text { com o consumo expetável de benefícios económicos incorporados no ativo } \\
\text { subjacente realizado pelo locatário? }\end{array}$ & \\
\hline Q4 & $\begin{array}{l}\text { Concorda que o princípio de consumo expetável do locatário deve ser aplicado } \\
\text { utilizando requisitos que diferem conforme o proprietário do ativo subjacente? }\end{array}$ & \\
\hline Q5 & Concorda com as propostas sobre prazo de locação? & \\
\hline Q6 & $\begin{array}{l}\text { Concorda com as propostas sobre a mensuração dos pagamentos de locação } \\
\text { variáveis? }\end{array}$ & \\
\hline Q7 & $\begin{array}{l}\text { Aquando da transição, concorda com a adoção de uma abordagem retrospetiva } \\
\text { modificada ou total para o reconhecimento e mensuração das locações? }\end{array}$ & \\
\hline Q8 & Concorda com os requisitos de divulgação propostos para locador/locatário? & \\
\hline Q9 & $\begin{array}{l}\text { Numa ótica de balanceamento custo-benefício, concorda isentar entidades não } \\
\text { cotadas da reconciliação de passivos de locação ou usar uma taxa de desconto } \\
\text { risk-free para mensurá-los? }\end{array}$ & \multirow{4}{*}{$\begin{array}{l}\text { Questões } \\
\text { acessórias: } \\
\text { Isenções, divulgações } \\
\text { adicionais e relações } \\
\text { da IFRS } 16 \text { com outras } \\
\text { matérias reguladas } \\
\text { em normas distintas }\end{array}$} \\
\hline Q10 & $\begin{array}{l}\text { Concorda que não é necessário estabelecer critérios de mensuração e } \\
\text { reconhecimento distintos para locações entre partes relacionadas? }\end{array}$ & \\
\hline Q11 & $\begin{array}{l}\text { Concorda que não é necessário fornecer divulgações adicionais para locações } \\
\text { entre partes relacionadas? }\end{array}$ & \\
\hline Q12 & $\begin{array}{l}\text { Concorda que o direito de uso de um ativo deve estar enquadrado no âmbito } \\
\text { da IAS } 40 \text { se a propriedade locada cumprir a definição de propriedade de } \\
\text { investimento? }\end{array}$ & \\
\hline
\end{tabular}


Assim, tendo em conta os objetivos inicialmente definidos e o referencial teórico divulgado na parte precedente, por um lado, assim como o modelo proposto para o desenvolvimento deste estudo, por outro, foi definida a seguinte hipótese geral:

Verificam-se diferenças significativas, indiciadoras de lobbying, entre os grupos de stakeholders participantes no processo de substituição da IAS 17 pela IFRS 16 (Locações) tendo em conta os distintos interesses (lobbies) de tais grupos.

Para efeitos de realização do estudo proposto, as questões foram analisadas por meio da sua transformação em variáveis ordinais (de "1" a “5”), tendo por base a escala de classificação proposta na Tabela 3 , igualmente representativa de uma escala do tipo "Likert".

Tabela 3

Escala de classificação das respostas

\begin{tabular}{cl}
\hline Classificação & \multicolumn{1}{c}{ Definição } \\
\hline 1 & Quando o respondente se apresenta em desacordo com o posicionalmente sugerido na questão \\
\hline 2 & Quando a resposta é apresentada sem posição aparentemente vinculativa por parte do respondente \\
\hline 3 & Quando a resposta à questão não é fornecida ou é omissa \\
\hline 4 & $\begin{array}{l}\text { Quando o respondente se apresenta parcialmente em acordo com o posicionalmente sugerido na } \\
\text { questão }\end{array}$ \\
\hline 5 & Quando o respondente se apresenta em acordo com o posicionalmente sugerido na questão
\end{tabular}

Como se denota, a classificação "3" (ponto central) encontra-se associada às "não-respostas ou omissões", representativos de uma não assunção de posição por parte do respondente e possibilitando a manutenção do respondente na população, encontrando-se os pontos extremos " 1 " e "5" como as posições contrárias ("em desacordo" e "em acordo", respetivamente). A classificação "2" representa uma posição intermediária entre os pontos "1", relativo às discordâncias, e "3", associado à não resposta. De notar-se que a "não resposta" poderá indiciar o menor interesse do respondente pelos potenciais impactos da questão em análise, sendo igualmente uma informação relevante a ser captada no contexto do estudo. Este procedimento fora anteriormente utilizado, designadamente, por Holder, Karim, Lin e Woods (2013). Em sentido oposto, Do Carmo et al. (2011) e Carvalho et al. (2015) optaram por uma escala dicotómica, atendendo a métodos ou objetivos distintos. No primeiro caso, os autores procederam à análise por via de uma regressão logística, tendo como variável dependente as decisões do Iasb após o processo de discussão ("1" se em linha com o comentário recebido; "0" em caso contrário). No segundo, a utilização do teste estatístico do qui-quadrado foi determinante na seleção da escala, que pretendia analisar apenas em que medida as respostas divergiam consoante o enquadramento profissional dos respondentes, sem analisar diretamente se opiniões emanadas indiciavam, ou não, a existência de lobbying.

Os dados foram submetidos a distintas técnicas estatísticas de análise, consoante os objetivos em causa. Técnicas de análise descritiva (univariada) foram utilizadas (frequências) de modo a analisar o padrão geral das respostas por parte dos distintos grupos de respondentes. Técnicas não paramétricas bivariadas como o Mann-Whitney-U e o Kruskal-Wallis, apropriado para variáveis com as características anteriormente descritas, procuram, por seu turno, identificar resultados mais robustos relativamente às diferenças entre os grupos de respondentes (dois a dois e entre os vários grupos, respetivamente).

O ponto seguinte deste artigo apresenta os principais resultados obtidos, à luz da metodologia anteriormente descrita. 


\section{Análise dos resultados}

A Tabela 4 apresenta as frequências relativas para a combinação questão/grupo de respondente/ respostas obtidas.

Tabela 4

Frequência relativa: questões, grupo de respondentes e respostas obtidas

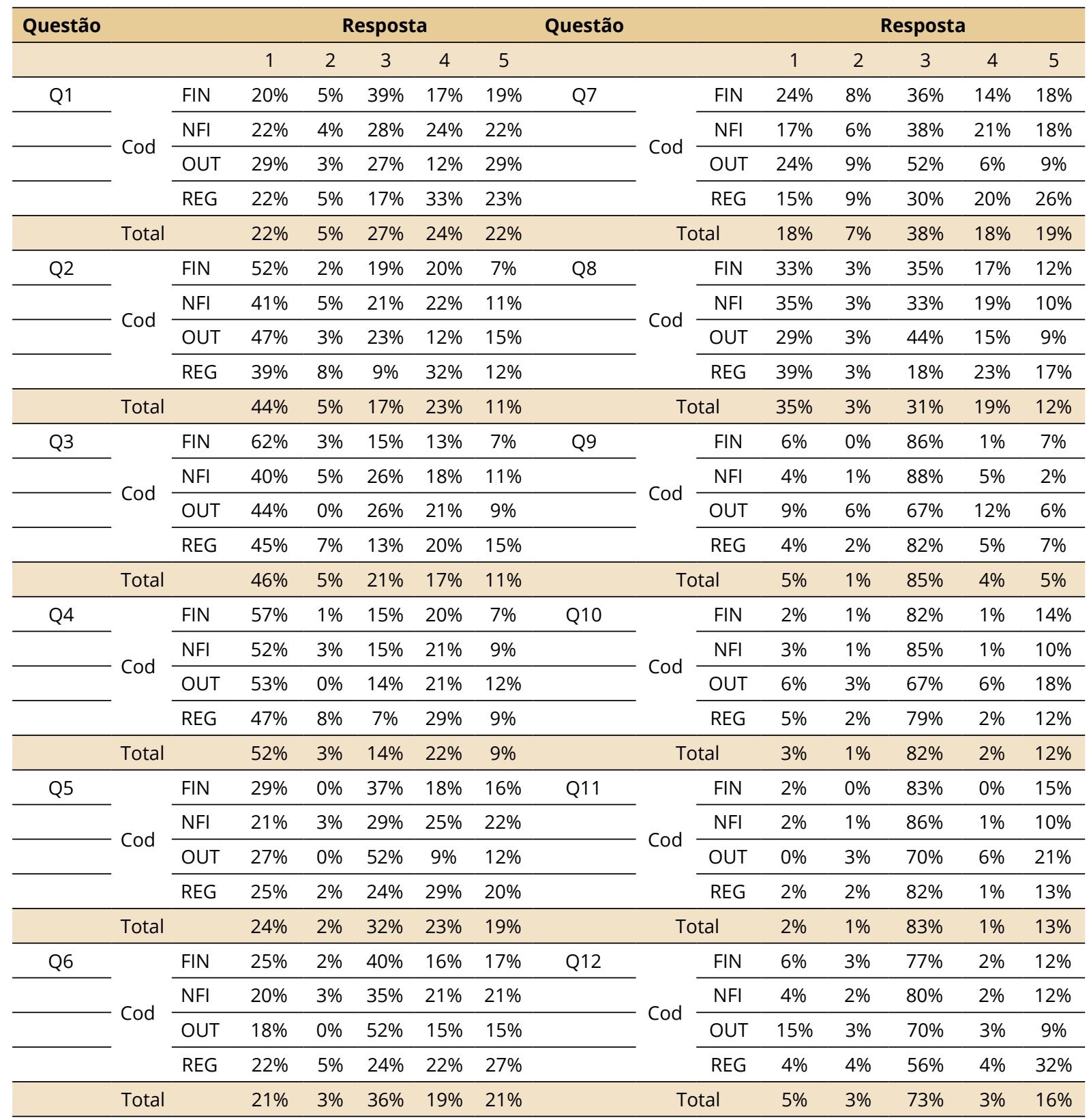


Destaca-se, de imediato, que de Q2 a Q4, mais diretamente associadas às matérias relativas ao reconhecimento e ao modelo de contabilização das locações, apresentam genericamente os maiores níveis de discordância ou não-vinculação (respostas "1" e "2"). As questões que cobrem aspetos relativos à identificação, prazos e mensuração das locações (Q1, Q5 e Q6, respetivamente), apresentam, por sua vez, os níveis de concordância genericamente mais elevados (respostas “4" e "5"). Um elevado nível de não resposta (resposta "3") é passível de ser identificado para Q9 a Q12 (com um mínimo de 74\% e um máximo de $85 \%$ ), associadas às matérias acessórias propostas no ED revisto (2013) (isenções, divulgações adicionais e relações da IFRS 16 com outras matérias reguladas em normas distintas), o que indicia uma maior "indiferença" relativamente a tais questões. Em uma análise por grupos, é possível aferir que o grupo "FIN" apresenta níveis de discordância superiores nas questões Q2 a Q4 referidas. De forma menos expressiva (com frequência relativa a variar entre $27 \%$ e $33 \%$ ), destaca-se a maior concordância, ainda que parcial, nas questões Q1 e Q5, e total, na questão Q6, do grupo "REG".

A Tabela 5 apresenta os níveis de significância obtidos a partir dos resultados do teste de Kruskal-Wallis, que identifica a existência de diferenças expressivas entre os grupos em análise. Com base em tais resultados, verifica-se que um terço das questões (Q3, Q5, Q7 e Q12) apresentam divergências transversais entre os grupos analisados a um nível de significância de 5\%, identificando-se adicionalmente diferenças também em termos da Q2, ainda que de forma menos expressiva. De notar-se que as primeiras questões (Q1 a Q8) encontram-se associadas, genericamente, com as questões principais da IFRS 16 (critérios de reconhecimento, mensuração e divulgação). Assim, a existência de divergências de opiniões de uma forma mais generalizada, conjugada com as conclusões anteriores, reforça, nesse âmbito, os indícios de um maior envolvimento das entidades na expressão dos seus posicionamentos (distintos) em torno dessas temáticas.

A análise preliminar de tais resultados, em linha com Hartwig (2012), permite aferir a existência de uma efetiva tentativa de influenciar o processo de normalização, materializada na particular oposição realizada pelo grupo "FIN" à Q2 e Q3 mencionadas, no sentido de impedir do modelo contabilístico proposto para os locatários, prejudicial aos seus interesses económicos. O elevado know-how deste grupo de entidades em matéria locações potencia a probabilidade de sucesso do efeito lobbying (Larson, 2008; Kothari et al. 2010).

Tabela 5

Teste de Kruskal-Wallis por grupos de respondentes (níveis de significância)

\begin{tabular}{|c|c|c|c|c|c|c|c|c|c|c|c|c|}
\hline Questão & Q1 & Q2 & Q3 & Q4 & Q5 & Q6 & Q7 & Q8 & Q9 & Q10 & Q11 & Q12 \\
\hline N.Sig. & 0,449 & 0,077 & 0,002 & 0,412 & 0,050 & 0,243 & 0,009 & 0,874 & 0,897 & 0,514 & 0,124 & 0,000 \\
\hline
\end{tabular}

No intuito de analisar em mais pormenor as diferenças entre os grupos em análise, combinados "dois a dois", o teste de Mann-Whitney foi adicionalmente aplicado. A Tabela 6 apresenta os níveis de significância obtidos a partir da realização do referido procedimento. 
Tabela 6

Teste de Mann-Whitney por pares de grupos de respondentes (níveis de significância)

\begin{tabular}{|c|c|c|c|c|c|c|c|c|c|c|c|c|}
\hline Questão & Q1 & Q2 & Q3 & Q4 & Q5 & Q6 & Q7 & Q8 & Q9 & Q10 & Q11 & Q12 \\
\hline NFI vs. FIN & 0,387 & 0,041 & 0,000 & 0,313 & 0,032 & 0,124 & 0,069 & 0,723 & 0,904 & 0,185 & 0,140 & 0,557 \\
\hline $\begin{array}{l}\text { NFI vs. } \\
\text { REG }\end{array}$ & 0,304 & 0,364 & 0,968 & 0,332 & 0,815 & 0,441 & 0,207 & 0,407 & 0,463 & 0,749 & 0,506 & 0,000 \\
\hline $\begin{array}{l}\text { NFI vs. } \\
\text { OUT }\end{array}$ & 0,809 & 0,580 & 0,875 & 0,893 & 0,041 & 0,514 & 0,018 & 0,910 & 0,944 & 0,284 & 0,029 & 0,091 \\
\hline $\begin{array}{l}\text { FIN vs. } \\
\text { REG }\end{array}$ & 0,099 & 0,013 & 0,003 & 0,089 & 0,115 & 0,066 & 0,015 & 0,687 & 0,523 & 0,453 & 0,525 & 0,000 \\
\hline $\begin{array}{l}\text { FIN vs. } \\
\text { OUT }\end{array}$ & 0,925 & 0,580 & 0,067 & 0,507 & 0,461 & 0,783 & 0,298 & 0,935 & 0,953 & 0,757 & 0,244 & 0,229 \\
\hline $\begin{array}{l}\text { REG vs. } \\
\text { OUT }\end{array}$ & 0,517 & 0,345 & 0,852 & 0,700 & 0,078 & 0,320 & 0,007 & 0,728 & 0,766 & 0,480 & 0,125 & 0,003 \\
\hline
\end{tabular}

Em termos gerais, os resultados apresentam-se consistentes com as evidências proporcionadas pelo teste de Kruskal-Wallis, na medida em que são as variáveis já anteriormente indicadas (Q3, Q5, Q7 e Q12) que apresentam diferenças em pelo menos três combinações (ainda que, em alguns casos, apenas a um nível de significância de 10\%), destacando-se nesse contexto Q7 e Q12, com diferenças em quatro combinações. Segue-se a variável Q2, com diferenças expressivas em duas combinações. As variáveis Q1, Q6 e Q11 apresentam diferenças significativas em apenas uma combinação (nos dois primeiros casos, apenas a um nível de significância de 10\%). Apenas as variáveis Q8 a Q10 não apresentam diferenças expressivas entre as combinações analisadas.

Analisando-se em mais pormenor as combinações propostas, verifica-se um maior número de diferenças em duas combinações, nomeadamente, as combinações "Não Financeiras (NFI) vs. Financeiras (FIN)" e "FIN vs. Reguladores (REG)". A observação das frequências relativas inseridas na Tabela 4, conjuntamente com o nível de significância do teste de Mann-Whitney, é um recurso útil na análise de tais resultados. Nesse contexto, ressalte-se que em ambos os casos as diferenças resultam de um maior nível de discordância por parte do grupo "FIN" em relação aos grupos "NFI" e "REG" para a generalidade das variáveis em que as diferenças se apresentam significativas, à exceção da Q12. Para esta última variável, o grupo "REG" diferencia-se dos demais pelo nível de concordância mais expressivo, ao mesmo tempo em que se apresenta como o grupo que mais resposta concedeu, em termos relativos, à referida questão. Tal facto leva mesmo a que este grupo se apresente sempre distinto dos demais no que à referida questão diz respeito. Tendo em conta que apenas nessa mesma questão (Q12) o grupo "NFI" se apresenta divergente do grupo "REG", e à luz das considerações iniciais, é possível concluir que estes dois grupos se apresentam genericamente mais consensuais no que à revisão do conteúdo da norma de locações diz respeito. Contrariamente, o grupo "OUT" apresenta um maior número de divergências em relação aos grupos "NFI" e "REG", por comparação ao grupo "FIN", com o qual diverge. O exposto relativamente à discordância das entidades financeiras, em oposição à maior concordância de reguladores e entidades não financeiras, corrobora a teoria positiva da Contabilidade (Watts \& Zimmerman, 1978), da agência (Jensen \& Meckling, 1976 e Fama 1980) e do comportamento racional (Klein, 1946). Nesse sentido, o hipotético impacto negativo na informação financeira dos locatários, designadamente, em termos de rácios econômico-financeiros e de reconhecimento e/ou divulgação de obrigações poderão justificar a posição de entidades financeiras, de acordo com Kort (2011).

O ponto seguinte deste artigo apresenta, por fim, as principais conclusões, limitações e potenciais contributos deste estudo para as futuras investigações neste campo. 


\section{Conclusões, limitações e perspetivas futuras}

O incremento da transparência, da comparabilidade e a redução da necessidade de ajustamentos ao relato financeiro para efeitos de análise, atualmente ainda realizados pelos diversos stakeholders no contexto da IAS 17, foram identificados pelo Iasb e Fasb como objetivos norteadores do projeto de substituição pela nova norma das locações: a IFRS 16. A nova norma procura, assim, obter uma ainda melhor representação da imagem verdadeira e apropriada da posição financeira e do desempenho das entidades.

Atendendo ao exposto, os resultados apresentados apontam para a existência de um maior nível de divergências significativas entre os grupos de entidades financeiras e não financeiras no que às questões mais centrais/relevantes da IFRS $16 \mathrm{diz}$ em respeito. Incluem-se nesse contexto, nomeadamente, as questões concernentes ao reconhecimento associado à existência de um modelo único ou dual de contabilização das locações por parte dos locatários e locadores (questões 2 e 3, respetivamente), de acordo com o consumo expetável de benefícios económicos incorporados no ativo subjacente e a utilização, à luz desse princípio, de requisitos diferenciados conforme o proprietário do ativo subjacente (questão 4).

É igualmente de destacar, nesse âmbito, o maior alinhamento entre as opiniões das entidades não financeiras e os reguladores, por oposição às diferenças verificadas entre estes últimos e as entidades financeiras. A constatação de tais diferenças entre os grupos encontra acolhimento em literatura anterior, nomeadamente, Do Carmo et al. (2011) e Carvalho et al. (2015), suportada por razões de lobbies perpetrados pelas distintas partes interessadas.

A análise detalhada de tais diferenças revela, designadamente, uma significativa oposição de entidades financeiras à questão 3 já atrás mencionada, relacionada com a aplicação, por parte do locador, de um modelo contabilístico distinto, de acordo com o consumo expetável de benefícios económicos incorporados no ativo subjacente realizado pelo locatário. Recorde-se que, como resultado final da norma, o modelo de contabilização das locações previsto na IAS 17 manteve-se em tais operações exclusivamente para os locadores. O exposto poderá traduzir a influência organizacional de que gozam este grupo de entidades no contexto regulatório específico desta norma, em linha, particularmente, com a teoria institucional preconizada por Bengtsson (2011).

As questões acessórias, que incluem matérias sobre as isenções, divulgações adicionais e relações da norma das locações com outras temáticas reguladas em normas distintas, obtiveram níveis de adesão diminutos, o que se associa ao desinteresse por partes dos distintos grupos em tópicos de influência direta mais diminuta na perceção dos investidores acerca das obrigações das entidades resultantes de locações.

Este trabalho apresenta algumas limitações. A primeira, inerente a estudos dessa natureza, diz respeito à subjetividade associada à classificação das respostas, quer em termos da caraterização dos respondentes, quer em termos da codificação à luz da escala proposta. Igualmente inseparável de estudos desta natureza, a possibilidade de os respondentes participantes no processo de discussão pública do Iasb não constituírem uma amostra representativa do universo de stakeholders de referência constitui outra limitação sob o ponto de vista do desenho da amostra que não pode deixar de ser referenciada.

As justificações económicas ou concetuais apresentadas pelos respondentes em matérias de relevante impacto financeiro, como é o caso das locações, representa outra possibilidade de continuidade deste estudo. Não tendo sido tal aspeto aqui analisado, a assimetria no tratamento previsto na IFRS 16 entre os locatários e locadores poderia ser avaliada à luz dos resultados obtidos e das eventuais consequências do exercício de loobying por parte das entidades financeiras, sendo esta uma proposta de continuidade para esta investigação. Adicionalmente, a análise das formas de operacionalização utilizadas nas estratégias de lobbying constituem oportunidades de investigação futura nesta área.

Aferir a existência de diferenças significativas de opinião indiciadoras de lobbying no âmbito de um projeto de substituição de norma promovido pelo Iasb, e em função dos distintos interesses envolvidos (lobbies), constitui, assim, o principal contributo da presente investigação. Adicionalmente, pode ser apontado como elemento de inovação deste estudo a análise igualmente efetuada do aparente comportamento dos respondentes face às perguntas apresentadas, tendo em conta o potencial interesse que tais questões despertam à luz das distintas temáticas que lhes estão subjacentes. 


\section{Referências bibliográficas}

Allen, A., Ramanna, K. \& Roychowdhury, S. (2014). Auditor lobbying on accounting standards. Harvard Business School Accounting \& Management Unit. Working Paper No. 15-055.

Anantharaman, D. (2015). Regular paper: Understanding the evolution of SFAS 141 and 142: An analysis of comment letters. Research in Accounting Regulation, 27 (2), pp. 99-110. DOI: https:IIdoi. org/10.1016/j.racreg.2015.09.001

Asekomeh, A., Russell, A. \& Tarbert, H. (2006). A critical analysis of the use of accounting standards' comment letters as lobbying tools by extractive industry firms. Petroleum Accounting and Financial Management Journal, 25(3), pp. 55-76. Recuperado em 23 abril, 2017, de: https://repository. abertay.ac.uk/jspui/handle/10373/70.

Bamber, M. \& McMeeking, K. (2016). An examination of international accounting standard-setting due process and the implications for legitimacy. The British Accounting Review, 48, pp. 59-73. DOI: https:IIdoi.org/10.1016/j.bar.2015.03.003

Bengtsson, E. (2011). Repoliticalization of accounting standard setting - The IASB, the EU and the global financial crisis. Critical Perspectives on Accounting, 22 (6), pp. 567-580. DOI: https:IIdoi. org/10.1016/j.cpa.2011.04.001

Carvalho C., Albuquerque, F., Texeira Quirós, J. \& Justino, M. (mai./jun./jul./ago. 2015). Uma análise das diferenças em termos dos interesses profissionais a partir do projeto de substituição da IAS 39. Revista Contabilidade Financeira - USP, 26(68), pp. 181-194. DOI: https:IIdoi.org/10.1590/1808$-057 \times 201500530$

Chatham, M., Larson, R. \& Vietze, A. (2010). Issues affecting the development of an international accounting standard on financial instruments. Advances in Accounting, 26 (1), pp. 97-107. DOI: https:\\ doi.org/10.1016/j.adiac.2010.03.002

Do Carmo, C., Mussoi, A., \& Carvalho, L. (2011). A influência dos grupos de interesse no processo de normatização contábil internacional: $\mathrm{O}$ caso do discussion paper sobre leasing. Anais Congresso USP de Controladoria e Contabilidade, 11. São Paulo, SP, Brasil. Recuperado em 23 abril, 2017, de: http:// repositorio.bc.ufg.br/handle/ri/416.

Donkersley, K., Ravelli, R., \& Buchanan, P. (2016). IFRS 16 Leases. [Em linha]. Recuperado em 20 abril, 2017, de: http://www.ifrs.org/Alerts/ProjectUpdate/Documents/2016/Webinar-IFRS-16-Leases.pdf.

Fama, E. (1980). Agency Problems and the Theory of the Firm. The Journal of Political Economy, 88(2), pp. 288-307. Recuperado em 25 abril, 2017, de:http://www.jstor.org/stable/1837292.

Fogarty, T. (1992). Financial accounting standard setting as an institutionalized action field: Constraints, opportunities and dilemas. Journal of Accounting and Public Policy, 11(4), pp. 331-355. DOI: https:Ildoi.org/10.1016/0278-4254(92)90003-G

Georgiou G. (2004). Corporate lobbying on accounting standards: Methods, timing and perceived effectiveness. ABACUS, 40(2), pp. 219-237. DOI: v10.1111/j.1467-6281.2004.00152.x.

Giner, B., Arce, M. (2012). Lobbying on accounting standards: Evidence from IFRS 2 on Shared-Based Payments. European Accounting Review, 21(4), pp. 655-691. DOI: https:I|doi.org/10.1080/096381 80.2012.701796

Hansen, B. (2010). Lobbying of the International Accounting Standards Board: An empirical investigation. DOI: https:I|doi.org/10.2139/ssrn.1081413 
Hartwig, F. (2012). Preparers' and Non-Preparers' Lobbying on the Proposed Prohibition of Goodwill Amortisation in ED3 'Business Combinations'. The Finnish Journal of Business Economics, 63(3-4), pp. 30-60. Recuperado em 23 abril, 2017, de:http://urn.kb.se/resolve?urn=urn:nbn:se:du-12549.

Hill, N., Shelton, S. \& Stevens, K. (2002). Corporate lobbying behaviour on accounting for stock-based compensation: Venue and format choices. ABACUS, 38(1), pp. 78-90. DOI: https:IIdoi. org/10.1111/1467-6281.00098

Holder, A., Karim, K., Lin, K. \& Woods, M. (2013). A content analysis of the comment letters to the FASB and IASB: Accounting for contingencies. Advances in Accounting, incorporating Advances in International Accounting, 29(1), pp. 134-153. DOI: https:I/doi.org/10.1016/j.adiac.2013.03.005

International Financial Reporting Standards (IFRS) (2016). Exposure Draft Leases (ED/2013/6). [Em linha]. Recuperado em 20 abril, 2017, de: http://www.ifrs.org/Current-Projects/IASB-Projects/Leases/Exposure-Draft-May-2013/Documents/ED-Leases-Standard-May-2013.pdf

International Financial Reporting Standards (IFRS) (2016a). IFRS 16 Leases: Effects analysis. [Em linha]. Recuperado em 16 novembro, 2017, de: http://www.ifrs.org/-/media/project/leases/ifrs/published-documents/ifrs16-effects-analysis.pdf.

Jensen, M. \& Meckling, W. (1976). Theory of the firm: Managerial behavior, agency costs and ownership structure. Journal of Financial Economics, 3(4), pp. 305-360. DOI: org/ https:IIdoi.org/10.1016/0304$-405 \mathrm{X}(76) 90026-\mathrm{X}$

Jorissen, A., Lybaert, N., Orens, R. \& Van Der Tas, L. (2012). Formal Participation in the IASB's Due Process of Standard Setting: A Multi-issue/Multi-period Analysis. European Accounting Review, 21(4), pp. 693-729. DOI: https:।|doi.org/10.1080/09638180.2010.522775

Kenny, S. \& Larson, R. (1993). Lobbying behaviour and the development of international accounting standards: The case of the IASC's joint venture project. European Accounting Review, 2(3), pp. 531-554. DOI: https: I|doi.org/10.1080/09638189300000050

Klein, L. (1946). Macroeconomics and the Theory of Rational Behavior. Econometrica, 14 (2), pp. 93-108. DOI: https:I/doi.org/10.2307/1905362

Kort, N. (2011). Self-interest in lobbying on accounting standards: The case of a new lease standard. Dissertação de Mestrado. Universidade de Tilburg, Holanda. Recuperado em 25 abril, 2017, de:http:// arno.uvt.nl/show.cgi?fid=120551.

Krippendorff, K. 1980. Content Analysis: An Introduction to Its Methodology. California, Sage Pulications, Inc.

Kothari, S., Ramanna, K. \& Skinner, D. (2010). Implications for GAAP from an analysis of positive research in accounting. Journal of Accounting and Economics, 50(2-3), pp. 246-286. DOI: https:IIdoi. org/10.1016/j.jacceco.2010.09.003

Larson, R. (2002). The IASC'S search for legitimacy: An analysis of the IASC'S standing interpretations Committee. Advances in International Accounting, 15, pp. 79-120. DOI: https:I|doi.org/10.1016/ S0897-3660(02)15020-3

Larson, R. (2007). Constituent participation and the IASB's International Financial Reporting Interpretations Committee. Accounting in Europe, 4(2), pp. 207-254. doi: https:Ildoi. org/10.1080/17449480701727981

Larson, R. (2008). An examination of comment letters to the IASC: Special purpose entities. Research in Accounting Regulation, 20, pp. 27-46. DOI: https: ||doi.org/10.1016/S1052-0457(07)00202-0 
Larson, R, \& Brown, K. (2001). Lobbying of the International Accounting Standards Committee: The case of construction contracts. Advances in International Accounting, 14, pp. 47-73. DOI: https:IIdoi. org/10.1016/S0897-3660(01)14005-5

Lloyd, S. (2016). Investor perspectives - A new lease of life. [Em linha]. Recuperado em 20 abril, 2017, de: https://dart.deloitte.com/resource/1/e93ed2dc-3f2f-11e6-95db-b1f180414c3d.

Mellado-Bermejo, L. \& Esteban, L. (2014). An exploratory study of countries participation intensity in comment-letters: Leases accounting proposal. Encuentro AECA: "Recuperação económica: confiança e investimento na Europa ”, 16. Leiria, Portugal. Recuperado em 26 abril, 2017, de: http://www. aeca1.org/ xviencuentroaeca/cd/59a.pdf.

Orens, R., Jorissen, A., Lybaert N. \& Van Der Tas, L. (2011). Corporate lobbying in private accounting standard setting: Does the IASB have to reckon with national differences?. Accounting in Europe, 8(2), pp. 211-234. DOI: https:\|doi.org/10.1080/17449480.2011.621672

Posner, R (1974). Theories of economic regulation. The Bell Journal of Economics and Management Science, 5(2), pp. 335-358. DOI: https:IIdoi.org/10.2307/3003113

Procházka, D. (2015). Lobbying on the IASB standards: An analysis of the lobbyists' behaviour over period 2006-2014. Copernican Journal of Finance \& Accounting, 4(2), pp. 129-143. DOI: https:Idoi. org/10.12775/CFJA.2015.020

Santos, O. \& Santos, A. (2014). Lobbying on accounting regulation: Evidence from the oil industry. Revista Contabilidade \& Finanças, 25(65). DOI: https: \\doi.org/10.1590/S1519-70772014000200004

Scott, W. (1987). The Adolescence of institutional theory. Administrative Science Quarterly, 32(4), pp. 493 511. DOI: https: \/doi.org/10.2307/2392880

Stigler, G. (1971). The Theory of Economic Regulation. The Bell Journal of Economics and Management Science, 2(1), pp. 3-21. DOI: https: Idoi.org/10.2307/3003160

Watts, R. \& Zimmerman, J. (1978). Towards a positive theory of the determination of accounting standards. The Accounting Review, 53(1), pp. 112-134. Disponível em http://lib.cufe.edu.cn/ upload_files/other/4_20140515041338_6\%20Watts,\%20R.\%20L.,\%20Zimmerman,\%20J.\%20 L.\%EF\%BC\%881978\%EF\%BC\%89Towards\%20a\%20Positive\%20accounting\%20theory\%20for\%20 the\%20determination\%20of\%20accounting.pdf.

Weber, R. (1990). Basic content analysis (Quantitative Applications in the Social Sciences), No. 49. California, Sage Publications, Inc. 